\title{
Los Cincuenta Años de Vida Literaria de José Ma. Chacón y Calvo
}

$\mathrm{E}$ L año de I962 llegaba José María Chacón y Calvo, el ilustre hombre de letras cubano, a sus setenta de vida; el pasado, 1963, a sus cincuenta de actividad literaria y de apostolado seglar de la cultura. Había nacido, en efecto, en 1892 , fecha del cuarto centenario del descubrimiento de América por España, coincidencia que tiene algo de simbólico en quien, como Chacón, ha sido un fervoroso puente espiritual entre las dos orillas del océano hispánico. Y en I9I3, cuando sólo contaba veintiún años de edad, publica su primer estudio definitivo, Los origene's de la poesía en Cuba, cuyo tema revela ya muy significativamente dos rasgos definidores de su autor: su interés por la literatura de su patria y su vocación por el rastreo amoroso e inteligente del pasado. El trabajo lo recogía Cuba Contemporáneá, la revista en la cual se abroquelaba la primera generación cubana de la República. Apenas salía de la adolescencia, y ya todos le respetaban por la seguridad y penetración de su labor. La reputación se extendió pronto al resto de América, y su nombre se alzó con entera justicia entre esa estirpe de preclaros humanistas de nuestras tierras que encabezan Alfonso Reyes y Pedro Henríquez Ureña. Cincuenta años de acendrado ejercicio literario, cuando se cuenta setenta de vida, acreditan la certeza de aquel juicio de Enrique José Varona según el cual el joven Chacón "produjo frutos delicados cuando todavía el mayor número apenas sabe gustarlos".1

La ocasión se presta, pues, a regocijo: saludar a un hombre que vive aún en la permanente $\mathrm{y}$ saludable juventud de su fe, de una fe puesta al servicio de los valores más altos del espíritu, aleccionando con su hacer constante $\mathrm{y}$ sin vacilaciones. $\mathrm{Y}$ al mismo tiempo, $\mathrm{y}$ ante todo, con su

1 E. J. V. Carta-prólogo a Ensayos sentimentales. San José de Costa Rica: J. Garcia Monge, Editor, 1923, p. 10. 
bondad. Los seres humanos se denuncian por las palabras de que gustan. Al maestro le place pensar en Martí como el "hombre angélico" de Cuba. $Y$ esto puede ser así porque tiene la sutil capacidad de reconocer en los otros esa rara cualidad que él lleva por dentro. No es la primera vez que se advierte esta disposición de su espíritu: "poseído de gracia evangélica" le veía hace años Ricardo Riaño Jauma, ${ }^{2}$ y como él tantos otros. Claro es que esta simple gracia, tan difícil sin embargo, no basta como carta de triunfo en el campo de la cultura; pero valdrá la pena sugerir que si todos repatan en ella, al hablar o escribir de Chacón, es sencilla. mente porque no resulta prenda común en los hombres que en ese campo se mueven ( $\mathrm{y}$ esto hay que admitirlo con profundo dolor). Otros hombres de América han hecho tanto o más que él por la misma causa de la inteligencia; pocos, en cambio, con tanta humanidad, con tan cordial sencillez, con esa franciscana humildad que le permite pasar con igual ascetismo por entre los halagos o las incomprensiones, atento sólo a la llamada interior de la verdad y la nobleza.

Aun a riesgo de repetir lo conocido por todos, he aquí una sumarísima nota biográfica de José María Chacón y Calvo. Nacimiento en Santa María del Rosario, villa cercana a la capital de Cuba, que él describe como la ciudad del silencio, "del largo silencio a todas horas". Estudios secundarios en el Instituto de La Habana. Encuentro alli con "el buen maestro", don Enrique Maza y Ledesma, al que evocará emocionadamente en uno de sus Ensayos sentimentales. Narrando sus primeras experiencias con el querido profesor que tanto le estimuló en el amor al libro, dice Chacón: "Fuimos olvidando así el respeto reglamentado, la vana y aparente disciplina, que tanto nos alejaba de los otros, y veíamos nacer en el corazón un cariño familiar, una confianza fecunda, una infantil gratitud hacia aquel maestro, el más anciano, el más bueno y el más humilde de todos". Grados universitarios en La Habana: doctor en Leyes y en Filosofía y Letras: contacto, en uno y otro mundo, con los dos maestros de su generación: González Lanuza y Varona. Pero para qué decir que, dado lo que habría de ser aquella universidad en los iniciales años republicanos, tan lastrados todavia de coloniaje, su formación tuvo que ser mayormente autodidáctica. Ya por entonces había publicado sus primeras críticas, era miembro de la Sociedad Filomática, escribía concienzudamente y disertaba sobre temas de investigación que antes sometía a muy seria revisión. No tardó, como se ha dicho, en

2 R. R. J. "José Matía Chacón y Calvo", en Revista de la Habana, Núm. VIII, 1946, p. 232. 
llegarle el reconocimiento de todos. Chacón quería elevar la tarea crítica llevando a ella lo que por entonces era nuevo en Cuba: el estudio y la disciplina en sustitución del vacío retórico y altisonante. $Y$ éste era mucho en aquellos confusos tiempos en que la República se estrenaba.

Después, año de r9r8: España. Nueve largos años de estancia, de primera estancia española. Razón burocrática: un cargo diplomático en la Legación de Cuba. Razón honda: la necesidad de apurar el encuentro de su sér de americano con sus irrenunciables orígenes históricos. Se abre el período de su trabajo fecundo y constructivo por los archivos y de sus viajes y correrías por toda España, nutriéndose espiritualmente de todo cuanto ella podía darle: sus paisajes, con sus playas y sus montes (el mar y la montaña, como en el título de un libro poético de Regino Boti, coetáneo y amigo de Chacón, han sido las dos grandes aficiones naturales de este deportista investigador), su pueblo, sus gentes humildes, su literatura. La clásica, claro está, pero también con la mirada vigilante a la que se hacía en su época. Y la época, para la poesía y las letras todas españolas, era en aquellos años del 1920 sin duda brillante. Chacón participa en ella: Rafael Alberti ha dedicado a esa participación una página afectuosa y más de una mención en su libro de memorias $L a$ arboleda perdida. De estos años data su amistad con Alfonso Reyes y Pedro Henríquez Ureña, mantenida fielmente hasta el final de la vida de estas dos cumbres de América. De entonces también son el acercamiento más íntimo a don Ramón Menéndez y Pidal y sus eruditas colaboraciones en la Revista de Filología Española.

Regreso a Cuba, vuelta a España, regreso a Cuba. Difícil seguirle en el recuento pormenorizado de su peripecia vital. En I934, cuando Cuba vivía los momentos convulsos y agitados que siguieron a la revolución de 1933 contra la tiranía de Machado, se produce su designación como Director de Cultura del Ministerio de Educación, posición que ocupará hasta I944, etapa en la que se convierte en la figura en torno a la cual gira la cultura oficial cubana. Después ocurrirá lo inevitable: la retirada al reducto más seguro de la iniciativa personal y privada. Viajes a España de nuevo, a los Estados Unidos (fue profesor visitante de Middlebury College en 1944), a Colombia. En Cuba: presidencia del Ateneo de La Habana, dirección de la Academia Cubana de la Lengua, correspondiente de la Española; del Instituto de Cultura Hispánica; decano de la Facultad de Filosofía y Letras en la Universidad Católica de Villanueva, en sus inicios, y profesor en ella de la cátedra de Literatura $\mathrm{Cu}$. bana hasta su cierre en r960. Hoy reside en su isla, tenaz y noblemente 
empeñado en salvar una tradición de cultura cuya preservación es para él acto de fe. Tal es, en síntesis, la historia externa del hombre Chacón y Calvo.

En cuanto a su obra, se ha hecho costumbre verla orientada en cuatro direcciones fundamentales: la crítica literaria, el ensayismo lírico, la investigación histórica y la empresa infatigable de animador de la: cultura, todas ellas presididas por esa escrupulosa seriedad que le granjeó: la merecida fama que ya de tan joven gozara. Sin embargo, cuantos a esa obra se han acercado incidental o provisionalmente (ahora por primera vez se la estudia con carácter sistemático como objeto de una tesis doctoral en la Universidad de Madrid) no se sienten inclinados a señalar ese rigor como la nota básicamente unificadora de las cuatro parcelas mencionadas. Sin negarlo en modo alguno, hay, no obstante, algo más hondo en todas ellas; y es ese empeño de Chacón por destacar lo humano esencial, la emoción personal y permanente que late en cualquier tema o género que toque. Todo se vuelve cálido en sus manos, todo se hace refracción de humanidad; y ello procede de su raigal disposición de ánimo frente al hecho de la cultura. Raimundo Lazo ha podido definir con aguda precisión esa unidad íntima de su espíritu: "Un espíritu de ancha, comprensiva y cordial tolerancia, un noble y persistente idealismo cruzan a través de toda su obra y, a la postre, la convietten en una emocionada y perenne evocación del pasado". ${ }^{3}$ Si, con tal que no entendamos esa evocación como nostálgico deleite de pasatista sino sostenida por la sana intención de arrojar desde el ayer luces y claridades que permitan conformar con mayor verdad y virtud el presente.

La crítica de la literatura fue la primera llamada de su vocación. Ya se dijo lo que en este terreno aportó: disciplina y profundidad, cuando todo en ella ostentaba improvisación y superficialidad, unidas al oportuno servicio de la intuición personal y del hallazgo propio. Una rápida ojeada a sus títulos muestra un equilibrio entre sus dos centros mayores de interés: Cuba y España. A las letras patrias dedicó sus pasos juveniles; y ahí están sus trabajos sobre los orígenes de la poesía cubana (I9r3); sobre los romances tradicionales en Cuba (I9I4); sobre Gertrudis Gómez de Avellaneda ( $19 \mathrm{r} 5$ ); y desde entonces, sus constantes asedios a Heredia, que le justifican como el primer herediano de América: José María Heredia (I9I5), Vida universitaria de Heredia (I9I6), "Del epistolatio de Heredia" (1926), "Nueva vida de Heredia" (1930), Estudios bere-

3 R. L. "Elogio de José Maria Chacón y Calvo", en Revista de la Habana, Núm. VIII, 1946, p. 225. 
dianos (I939), "El horacianismo en la poesia de Heredia" (I940), "Heredia y su ensayo sobre la novela" (r942). En esta línea hay que situar dos de sus libros definitivos: los Ensayos de literatura cubana y Las cien mejores poesias cubanas, ambos publicados en Madrid en I922. Este último, reeditado en 1958 por el Instituto de Cultura Hispánica de Madrid, se convirtió en seguida en una fijación importantísima de valores para la poesía cubana del siglo XIX, marcando un hito obligado en esta materia. El otro tema capital, España, le ganó también muy pronto; y de I9I7 es ya su trabajo sobre "Cervantes y el romancero", al que siguió su libro Ensayos de literatura española (Madrid, I928). Se ha ocupado también del Padre Sarmiento y del Poema del Cid (r934), de Sánchez Albornoz y su obra de medievalista (I935), de Quevedo y la tradición senequista (I947); de una variedad, en fin, de temas peninsulares.

La cita se ha hecho a vuelo de pájaro y habrán quedado muchos títulos sin mencionar. Dos observaciones, sin embargo, sí me parecen insoslayables. Una es destacar su interés por las expresiones puras del pueblo, por el folklore y la tradición; interés despertado muy tempranamente y mantenido hasta siempre: de r955 es su medular estudio "La poesía de Martí y lo popular hispánico". La otra sería llamar la atención a cuán devotamente se ha vuelto Chacón y Calvo, una y otra vez, hacia aquellos cubanos insignes del siglo xrx, algunos de ellos mentores de su propia generación, en los cuales sabe él que se encuentra la sustancia salvadora de la buena y legítima cubanía. En estos casos, no se trata sólo de ensayar una apreciación crítica sobre esas figuras, por seria que fuere. Es más bien el deseo de contribuir a levantar el edificio ideológico y moral de su patria lo que le impulsa. Todavía viene trabajando en los últimos años sobre Domingo del Monte, el Padre Varela, Luz y Caballero, Eliseo Giberga, Varona, Manuel Sanguily, Rafael Montoro. Todavía hace, o intenta, que las jóvenes generaciones cubanas se alimenten de lo más valioso y nutricio de su genuina tradición cultural.

Ahora vendría el ensayista íntimo, sentimental. Por aquí corre la vena más pura y lírica de su obra, devuelta en una prosa de serenas y armoniosas resonancias. Su primera experiencia personal de España se traduce en un libro emocionado: Hermanito menor (Costa Rica, I9I9). Es un recuerdo airoso del paisaje español; pero también de sus gentes $y$, entre éstas, de aquel pequeñuelo que le enseñó a ver y sentir mejor ese-paisaje: "Junto al valle y a las selvas de Lanuza veo un paseo largo -escribe-, junto a un gran río, un paseo lleno de árboles, un rebaño 
paciendo a lo lejos y un niño que va enseñándome todo, y que cuando me habla de algo parece que antes pasa por su corazón". Después hay que referirse a sus Ensayos sentimentales (Costa Rica, 1923). Son evocaciones luminosas, escritas desde el corazón, de muchas cosas que quedaron en su autor para siempre: lugares y situaciones, como Santa María del Rosario o Santillana del Mar; personas que se cruzaron en su vida: el buen maestro, Alfonso Reyes, José de Armas; lecturas indelebles: Luisa Pérez de Zambrana, Maragall, el poeta de Soria. Entique Díez Canedo, comentando estos ensayos, afirmaba: "Más escritura que en Hermanito menor, pero en el buen modo; es decir, más exigencias con la pluma para que no se desmande. Ningún silencio quizá; y del canto, sólo el tema, contado en prosa limpia". ${ }^{4} \mathrm{Y}$, por fin, mucho después, Diario en la muerte de mi madre (La Habana, I953), producto de la honda huella que le dejara tan doloroso suceso. Un reseñador anónimo veía certeramente en este Diario "un libro de transparencias estelares, de intimidad de cabezal materno donde está, limpia y plenamente vertida, toda la ternura, la infinita ternura de Chacón y Calvo. No es, no, la ternura de un literato. Es, simplemente, la ternura de un hombre". 5

Pero este hombre, tierno y sensible hasta las lágrimas, ha sido también un incansable andariego por los archivos españoles de Sevilla y Simancas; y una buena parte de su renombre de erudito le viene de sus sólidas contribuciones en ese espinoso quehacer. Buceador de los orígenes, le llamó particularmente aquella etapa de la historia americana por la que ésta se vincula a su raíz española; defensor de los valores humanos permanentes, puso su mayor devoción en aquellos hombres que representaban la España clara y mejor: Montesinos, Las Casas, Vitoria. Producto de una paciencia encomiable y de una gran agudeza en el discernimiento es su impottante Cedulario cubano. Los orígenes de la colonizacion (Madrid, r929), "obra de gran diligencia y fervor", como la definiera Homero Serís, ${ }^{6}$ en que su realizador resume "documentos que se refieren a sucesos que no han sido recogidos por las historias particulares de Cuba" y otros "por tener influencia fundamental en las doctrinas de la colonización". La preocupación por estas doctrinas informa también uno de sus mayores aportes en esta zona: "Criticismo y colonización" (Revista de la Universidad de La Habana, r935), así como un buen número de ensayos que revelan la constancia en nuestro autor de esa

4 E. D. C. "José María Chacón y Calvo", España, 9 de junio de 1923.

5 En la revista Orto. Manzanillo, Cuba, XİI, Núm. 11-12, 1953.

6 H. S. En Revista de Filología Española, Núm. XIX, 1932, pp. 201-202. 
preocupación: :"El Consejo de Indias y la historia de América" (Boletín de la Biblioteca de Menénd'ez y Pelayo, II, I932), "Ideario de la colonización" (Revista Bimestre Cubana, I933), "La experiencia del indio" (Publicaciones de la Asociación Francisco de Vitoria, 1934), "Cartas censorias de la conquista" (Revista Cubana, r938), etc. No puede pasarse por alto la mención aquí de $E l$ documento y la reconstrucción bistórica (La Habana, 1927) que, al par de ser un estudio ajustado con toda exactitud a su título, es una clave para vislumbrar la poesía ínsita en ese afanoso hurgar por los papeles donde yacen, callados, el pasado y el presente del hombre actual.

Queda por decir algo de su gestión como animador de la cultura. Todos tecuerdan su paso por la Dirección de Cultura cuando Cuba se desangraba - trágico destino de nuestro infortunado continente- en odios civiles y disensiones políticas. Con ser tan positivas sus realizaciones en el desempeño de su encomienda (la publicación de la Revista Cubana, de los Cuadernos de Cultura, la creación de la cátedra libre Enrique José Varona, aquella memorable Exposición de Pintura y Escultura, el paso y estancia por La Habana de figuras como Juan Ramón Jiménez, Menéndez y Pidal, Carl Vossler, Gabriela Mistral, Pedro Henríquez Ureña), lo de mayor relieve fue su casi milagroso papel de restaurador y pacificador de la inteligencia, uniendo los nombres más distantes, en ese caótico momento de $x 934$ cuando, tras la gesta del 33, "cesa lo histórico y comienza a recuperar su primado en los destinos cubanos la politicidad". " La frase entrecomillada es de Antonio S. Bustamante y Montoro (quien podría haber escrito "politiquería", con mayor verdad), en el homenaje que los intelectuales de Cuba rendían ya en I935, al término sólo de un año de eficaz labor, al hombre que culturalmente les había unido de nuevo. En esa faena conciliatoria residió, sobre todo, el éxito mayor de Chacón. A ella se ha referido pintorescamente Lino Novás Calvo: "Un gobierno militarista le encargó la Dirección de Cultura, y con su palabra, su ejem. plo y amor atrajo a los hombres de los cuatro puntos extremos y cardinales y en su Departamento se dieron la mano (aun cuando fuera se dieran de tiros)". 8

A ese triunfo suyo en la práctica, reconocido por todos, ha ligado siempre Chacón su tesis de la neutralidad de la cultura, tan discutida, que ha expuesto en numerosas ocasiones y a la cual aún se le ve hoy heroica-

7 A. S. B. M. "Discurso en el homenaje a José Maria Chacón y Calvo". En Revista Bimestre Cubana, XXXVI, 1935, p. 38.

8 L. N. C. "José María Chacón y Calvo. El peregrino de los archivos". En Revista Cubana, Núm. V, 1936, pp. 258-259. 
mente aferrado. Tal vez, como ha señalado con acierto Raimundo Lazo, lo que anda mal en ella sea su nombre, su designación (por cuanto la cultura nunca puede ser neutral), no su contenido intrínseco. Lazo ha deseado echar un poco de luz sobre esa tesis tan querida de Chacón, y ha conseguido traducirla en los mejores términos, refiriéndola inexcusablemente a la ejecutoria misma de su formulador: "Los hechos de Chacón y Calvo, más que sus palabras, nos dicen que a las actividades culturales hay que concurrir con nuestro aporte, definidos, beligerantes, sin ignorar nunca los intimos e innumerables enlaces entre la cultura y la vida; pero categóricamente dispuestos también a la imprescindible convivencia, la cual no puede fundarse, por cierto, sólo en la sublimación de ningún código de urbanidad y buenas costumbres, sino en el fiel sometimiento al imperio de la razón, opuesto a todas las formas de la violencia, de la insinceridad $y$ el sofisma, $y$ en el respeto a la libertad y dignidasd esencial del hombre". ${ }^{9}$ Valederas palabras éstas del distinguido profesor y crítico, para todos los tiempos. Tanto como las del propio Chacón: "Las ideas no deben ser causa de separación entre los hombres: sólo debe serlo la conducta". ${ }^{10}$ ¿Pero hasta qué punto será posible, boy, separar las ideas de la conducta, en una época en que precisamente lo ideológico se resuelve de inmediato en una forma, positiva o negativa, de acción? Desembarazado al fin de sus obligaciones oficiales, Chacón ha continuado (desde la tribuna del Ateneo de La Habana y desde las páginas del Boletin de la Academia Cubana de la Lengua) calorizando con igual entusiasmo todos los esfuerzos intelectuales que le ha sido dable auspiciar.

Hunter College.

\section{José OLIVIO JimÉNEZ}

9 Loc. cit., p. 229.

10 Citado por Lino Novás Calvo, loc. cit., p. 275. 